\title{
Research on Microstructure Transformation of Super304H Stainless Steel in the Process of Aging at $700^{\circ} \mathrm{C}$
}

\author{
Ni Jinfei ${ }^{1}$ \\ NO. 2 Inspection Department \\ Guangzhou Special Pressure Equipment Inspection Institute \\ Guangzhou, China \\ Jinfeini_gz@163.com \\ Li Maodong $^{1}$ \\ NO. 2 Inspection Department \\ Guangzhou Special Pressure Equipment Inspection Institute \\ Guangzhou, China \\ lmd92791@21cn.com
}

\author{
Li Hua ${ }^{1}$ \\ NO. 2 Inspection Department \\ Guangzhou, China \\ gzlihua63@163.com \\ Wang Zhiwu ${ }^{2}$ \\ Power and Mechanic College \\ Wuhan University \\ Wuhan, China \\ wzw1618@163.com
}

Guangzhou Special Pressure Equipment Inspection Institute

\begin{abstract}
To study microstructure transformation of Super304H, the original sample and the samples aging for $500 \mathrm{~h}, 800 \mathrm{~h}, 1500 \mathrm{~h}, 2500 \mathrm{~h}$ and $3650 \mathrm{~h}$ at $700{ }^{\circ} \mathrm{C}$ were analyzed with OM, SEM, TEM and X-ray diffractometry. The results showed the grain size and the precipitated phases along boundaries increased as aging time prolonged, the area fraction and the amount of precipitated phases increased remarkably, while the type of precipitated phases changed from $\mathrm{M}_{23} \mathrm{C}_{6}$ to $\mathrm{Cr}_{23} \mathrm{C}_{6}$ and $\mathrm{Nb}(\mathrm{C}, \mathrm{N})$ as aging time varied from $500 \mathrm{~h}$ to $3650 \mathrm{~h}$. The functional relation between area fraction of precipitated phases and aging time at $700^{\circ} \mathrm{C}$ was also given.
\end{abstract}

Keywords-Super 304H; Microstructure; Transformation; Aging; Precipitated Phase

\section{INTRODUCTION}

Super304H stainless steel has been widely used in hypercritical and ultra-supercritical power units for its comprehensive performance at high temperature [1-3]. But long time working at high temperature and high pressure will lead to its microstructure transformation and aging which could cause facility failure [4-5]. Compared to TP304H, TP347HFG and other heat resistant austenitic stainless steels, some elements, such as $\mathrm{Cu}, \mathrm{Nb}$ and $\mathrm{N}$ in Super $304 \mathrm{H}$, make the formation of precipitation of carbide and intermetallic compounds much more complicated [411]. It's significant to research the microstructure transformation of Super304H austenitic stainless steel for supervising the damage level of tubes in service.

\section{EXPERIMENTAL METHOD}

Original Super304H stainless steel tube used for this aging experiment is in accordance with the standard of ASTM A-213M (TABLE I). Its specification is OD45mm $\times 8 \mathrm{~mm}$. Using wire-electrode cutting machine, six tubesections with $200 \mathrm{~mm}$ long were obtained, and five of them were aging treated for $500 \mathrm{~h}, 800 \mathrm{~h}, 1500 \mathrm{~h}, 2500 \mathrm{~h}$ and
$3650 \mathrm{~h}$ respectively. To accelerate the microstructure transformation, the aging temperature was $700^{\circ} \mathrm{C}$. Then six samples were analyzed with OM, SEM, TEM and X-ray diffractometry successively. The instrument as showed in Fig.1 was designed and used to extract precipitated phases powder for X-ray diffraction analysis.

TABLE I. Composition of Super304H

\begin{tabular}{ccc}
\hline Composition (wt \%) & $\begin{array}{c}\text { Super304H } \\
\text { (ASTM A-213M) }\end{array}$ & Actual value \\
\hline $\mathrm{C}$ & $0.07 \sim 0.13$ & 0.10 \\
$\mathrm{Si}$ & $\leq 0.03$ & 0.25 \\
$\mathrm{Mn}$ & $\leq 1.00$ & 0.80 \\
$\mathrm{P}$ & $\leq 0.040$ & 0.032 \\
$\mathrm{~S}$ & $\leq 0.010$ & 0.032 \\
$\mathrm{Cr}$ & $17.00 \sim 19.00$ & 18.3 \\
$\mathrm{Ni}$ & $7.50 \sim 10.50$ & 8.62 \\
$\mathrm{Mo}$ & - & 0.16 \\
$\mathrm{Cu}$ & $2.50 \sim 3.50$ & 2.38 \\
$\mathrm{Nb}$ & $0.20 \sim 0.60$ & 0.49 \\
$\mathrm{~N}$ & $0.05 \sim 0.12$ & - \\
\hline
\end{tabular}




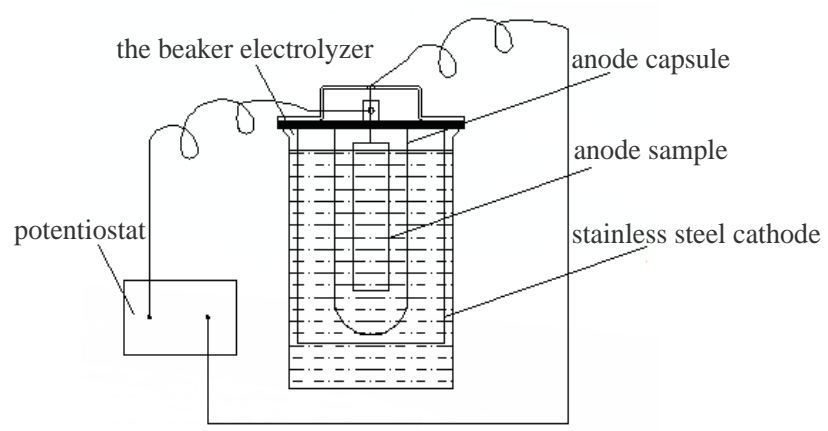

Figure 1. Instrument for Precipitated Phases Powder Extraction

\section{DISCUSSION}
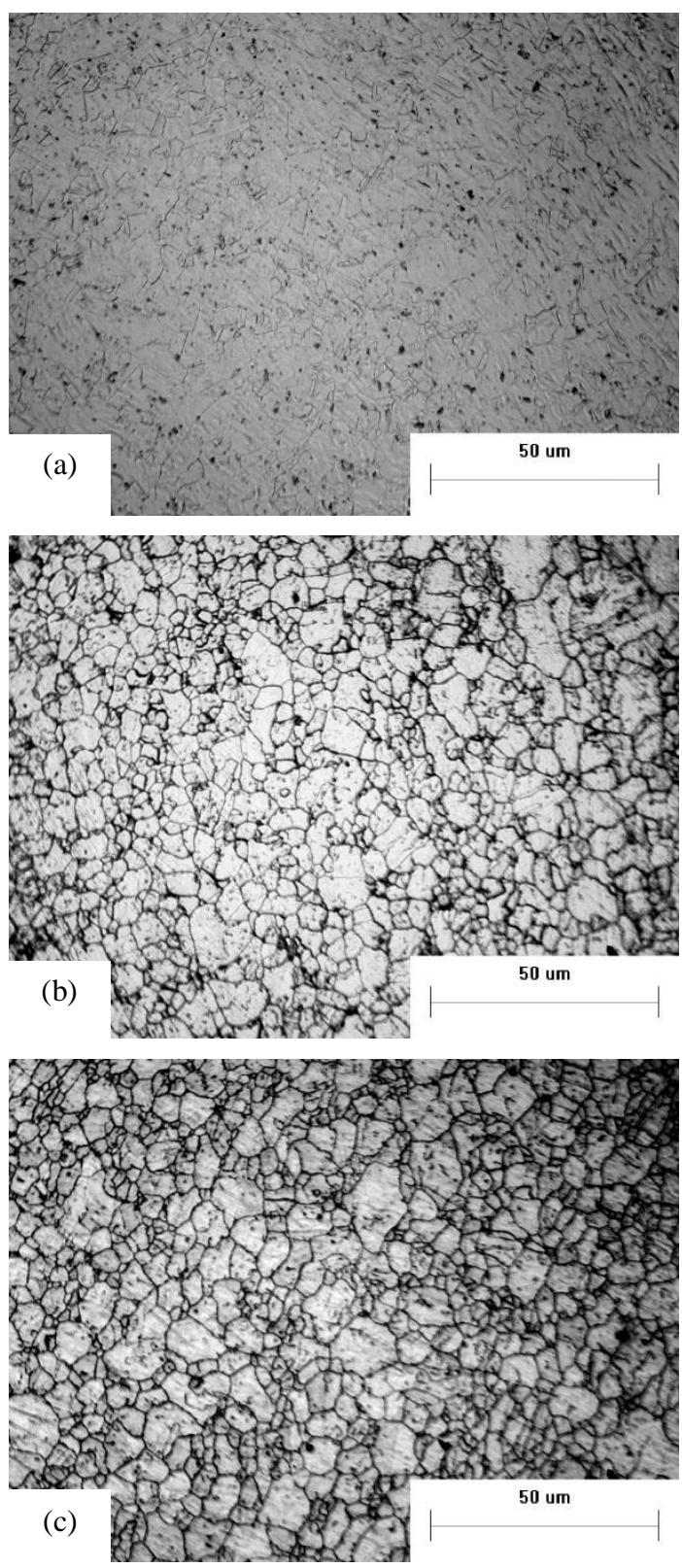

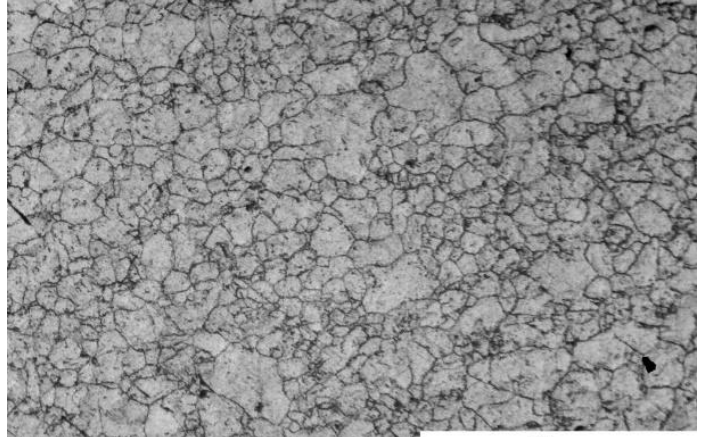

(d)
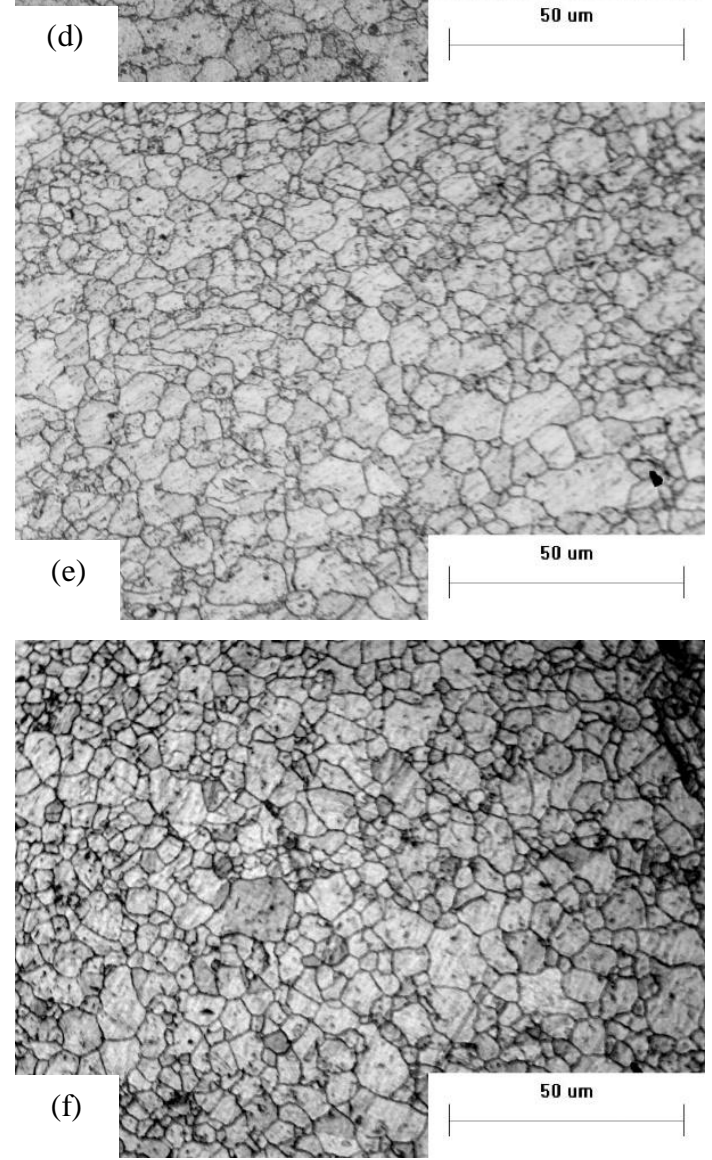

Figure 2. Metallurgical Structure of Original and Aging Treated Super304H Samples

(a)Original, (b)Aging for 500h, (c)Aging for $800 \mathrm{~h}$, (d)Aging for $1500 \mathrm{~h}$, (e)Aging for $2500 \mathrm{~h}$, (f) Aging for $3650 \mathrm{~h}$

Fig.2 (a) $\sim$ (f) show the optical microstructure (especially twins) transformation of Super304H aging for different time at $700^{\circ} \mathrm{C}$. The original sample has fine and multitudinous twins, and their boundaries are linear. After being treated for $500 \mathrm{~h}$, the size of twins increased, while their number decreased. After aging for $800 \mathrm{~h}$, the grains grew up consistently, their size tended to be identical, and those with abnormal dimension increased in number as well. Then the twins almost diminished, while large grains emerged and precipitated phases distributed along boundaries after $3650 \mathrm{~h}$ aging treatment. 

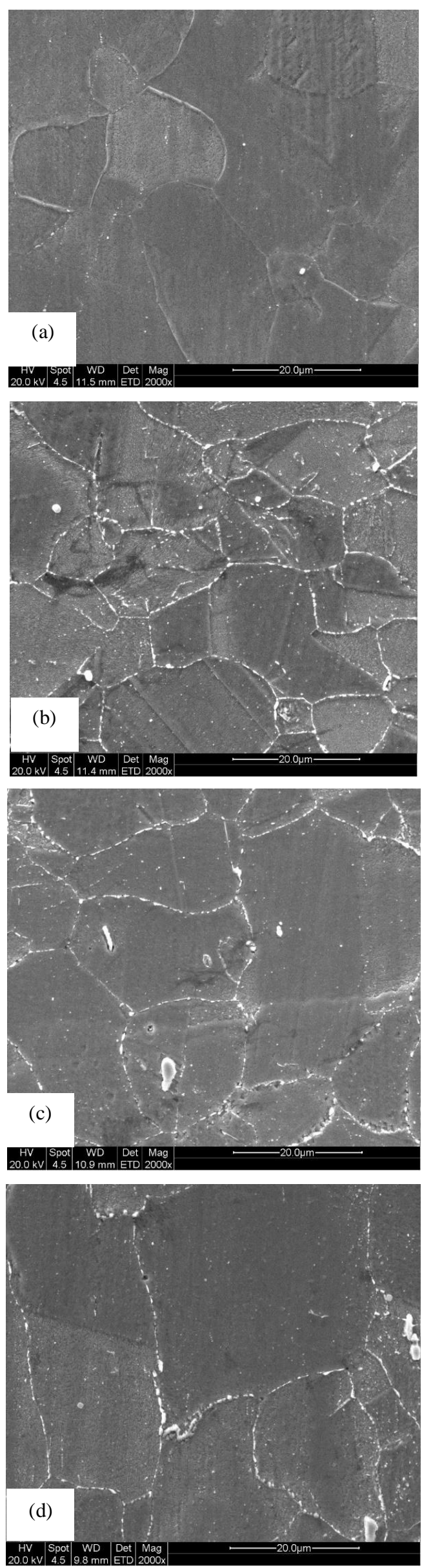
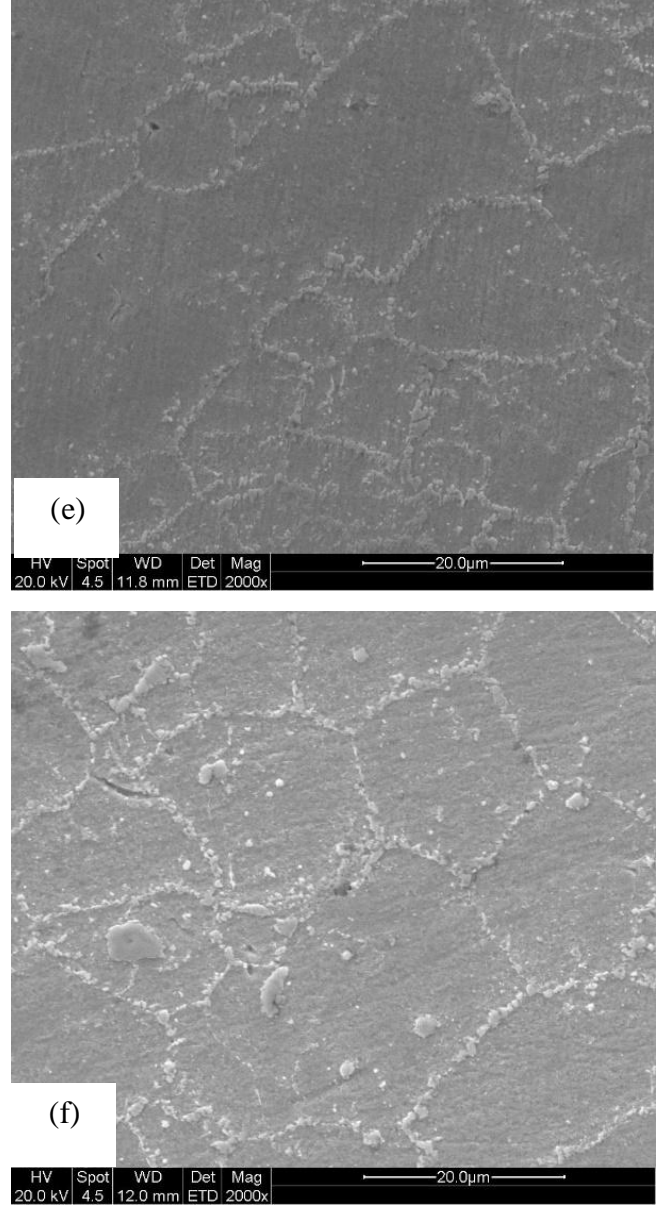

Figure 3. Microstructure of Original and Aging Treated Super304H Samples with SEM

(a)Original, (b)Aging for 500h, (c)Aging for $800 \mathrm{~h}$, (d)Aging for $1500 \mathrm{~h}$, (e)Aging for $2500 \mathrm{~h}$, (f) Aging for $3650 \mathrm{~h}$.

It is revealed from Fig.3(a) $\sim(\mathrm{f})$ that the precipitated phases along boundaries increased dramatically as aging time prolonged. Compared with Fig. 2, we can see that the patterns under OM and SEM are corresponding. Based on quantitative analysis of those photographs, the curves of relationship between the amount, the average size and the area fraction of precipitated phases with aging time could be given as Fig.4 and Fig.5.

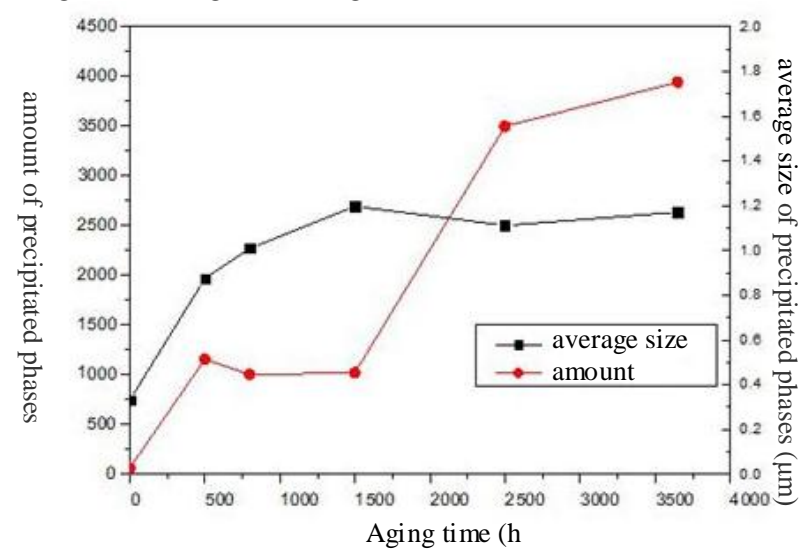

Figure 4. The Curve of Relationship between the Amount and the Average Size of Precipitated Phases with Aging Time 


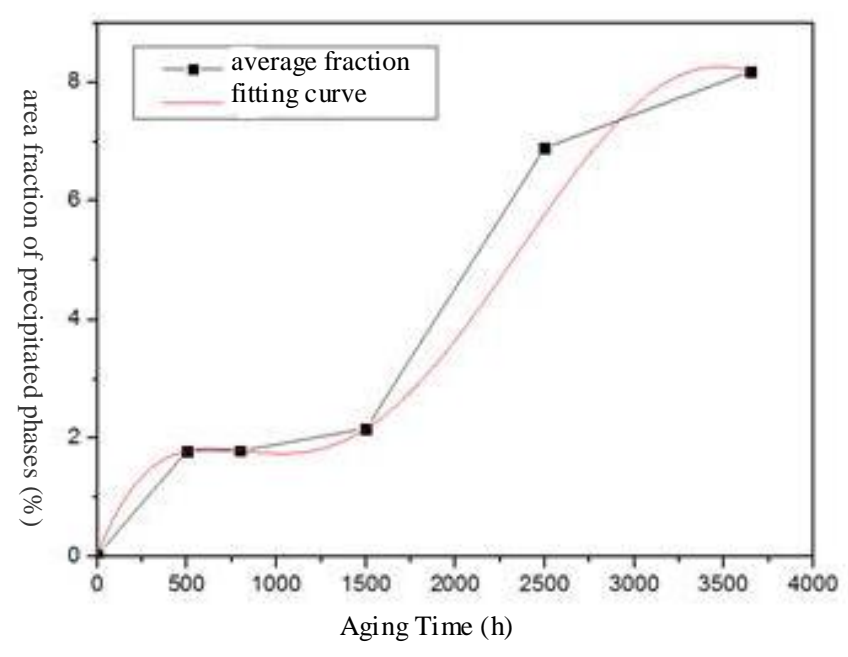

Figure 5. The Curve of Relationship between the Area Fraction of Precipitated Phases with Aging Time

The functional relation between the area fraction of precipitated phases (y, unit: \%) and aging time (x, unit: h) can also be derived from the fitting curve in Fig.5. That is

$$
\begin{aligned}
& y=0.036+0.78 \times 10^{-3} x-1.20 \times 10^{-5} x^{2}+7.61 \times 10^{-9} x^{3} \\
& -1.85 \times 10^{-12} x^{4}+1.53 \times 10^{-16} x^{5}
\end{aligned}
$$

From Fig.4 and Fig.5, we can see the amount and average size of the precipitated phases increased as aging time prolonged. The highest incremental speed of the amount emerged when the sample treated for $1500 \mathrm{~h}$ to $2500 \mathrm{~h}$. Meanwhile, after aging for $1500 \mathrm{~h}$ or longer, the average size of precipitated phases became stable.
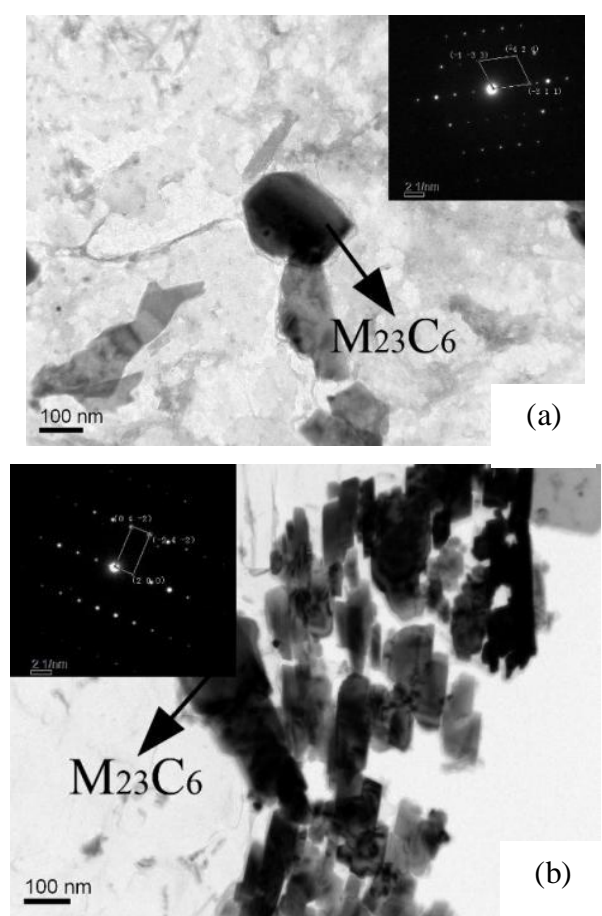
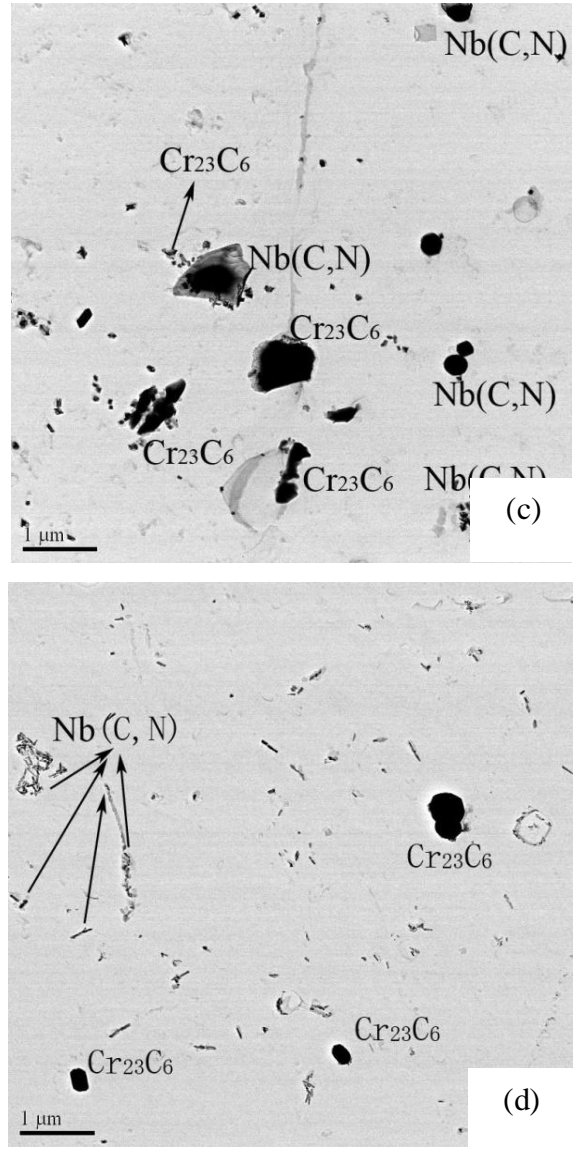

Figure 6. Patterns and Calibration of the Precipitated Phases in the Samples with Different Aging Time at $700^{\circ} \mathrm{C}$

(a) Aging for 500h, (b)Aging for $1500 \mathrm{~h}$, (c)Aging for $2500 \mathrm{~h}$, (d) Aging for $3650 \mathrm{~h}$

Furthermore, we analyzed TEM patterns and calibrated the diffraction patterns of precipitated phases in the samples with different aging time at $700^{\circ} \mathrm{C}$ (Fig.6). The results showed that the main precipitated phases in the sample being treated for $500 \mathrm{~h}$ are scattered and fine M23C6, while those in the sample treated for $1500 \mathrm{~h}$ are clustered M23C6. When the sample being treated for $2500 \mathrm{~h}$ and $3650 \mathrm{~h}$, the precipitated phases became clustered $\mathrm{Cr} 23 \mathrm{C} 6$, fine and scattered $\mathrm{Nb}(\mathrm{C}, \mathrm{N})$.

\section{CONCLUSION}

(1) As aging time prolonged at $700^{\circ} \mathrm{C}$, the grain size of Super304H increased and the precipitated phases along boundaries manifolded.

(2) In the samples being treated for $1500 \mathrm{~h}$ and $2500 \mathrm{~h}$ at $700^{\circ} \mathrm{C}$, the area fraction and the amount of precipitated phases increased remarkably.

(3) The type of precipitated phases changed from M23C6 to $\mathrm{Cr} 23 \mathrm{C} 6$ and $\mathrm{Nb}(\mathrm{C}, \mathrm{N})$ as aging time varied from $500 \mathrm{~h}$ to $3650 \mathrm{~h}$ at $700^{\circ} \mathrm{C}$.

(4) The functional relation of area fraction of precipitated phases (y, unit: \%) with aging time (x, unit: h) at $700^{\circ} \mathrm{C}$ could be given as

$$
\begin{aligned}
& y=0.036+0.78 \times 10^{-3} x-1.20 \times 10^{-5} x^{2}+7.61 \times 10^{-9} x^{3} \\
& -1.85 \times 10^{-12} x^{4}+1.53 \times 10^{-16} x^{5} .
\end{aligned}
$$




\section{REFERENCES}

[1] F. Masuyama, "History of Power Plants and Progress in Heat Resistant Steels". ISIJ Int., vol. 41(2001), NO. 6, pp. 612 625.

[2] R. Viswanathan and W. T. Bakker, "Materials for Boilers in Ultra Supercritical Power Plants", Proc. of 2000 International Joint Power Generation Conferences, Miami Beach, Florida, 2000, IJPGC2000-15049, pp. 1 14.

[3] Y. Sawaragi, "The Development of a New 18-8 Austenitic Stainless Steel with High Elevated Temperature Strength for Fossil Fired Boilers". Mechanical Behavior of Material. 4, 1991, pp.589594.

[4] SC Cheng, ZD Liu, and HS Bao, "Effect of Carbon Content and Niobium Content on Intergranular Corrosion of ASME S30432 Austenitic Heat Resistant Steel", Symposium on Heat Resistant Steels and Alloys for USC Power Plants 2007, Seoul, Korea, 2007, pp. $201 \sim 207$.

[5] ZD Liu and SC Cheng, "Research and Development of Advanced Boiler Steel Tubes and Pipes Used for $600^{\circ} \mathrm{C}$ USC Power Plants in China", Iron and Steel, vol. 45(2010), pp. 1-8.
[6] Chi Chengyu, Yu Hongyao and Xie Xishan, "Research and Development of Austenitic Heat-resistant Steels for $600{ }^{\circ} \mathrm{C}$ Superheater and Reheater Tubes of USC Power Plant Boilers", World Iron and Steel, vol. 4(2012), pp. 50-63.

[7] Gibbons T B, "Superalloys in Modern Power Generation Application",Materials Science and Technology, vol. 25(2009), pp. 129-135.

[8] Tan Shuping, Wang Zhenhua and Chen Shichang, "Processing Maps and Hot Workability of Super304H Austenitic Heat-resistant Stainless Steel", Materials Science and Engineering, vol. 517(2009), pp. 312-315.

[9] Viswanathan R, Coleman K and Rao U, "Materials for Ultrasupercritical Coal-fired Power Plant Boiler", Inter Journal of Pressure Vessels and Piping, vol. 83(2006), pp. 778-783.

[10] Viswanathan R, "Materials Technology for Coal-fired Power Plants", Advanced Material and processes, vol. 162(2004), pp. 7376.

[11] Soutmail T, "Precipitation in Creep Resistant Austenitic Stainless Steel”, Materials Science and Technology, vol. 17(2001), pp.1-17. 